\title{
Movements Resembling Orientation or Avoidance Elicited by Electrical Stimulation of the Superior Colliculus in Rats
}

\author{
Niaz Sahibzada, Paul Dean, and Peter Redgrave \\ Department of Psychology, University of Sheffield, Sheffield S10 2TN, England
}

Some studies have reported that stimulation of the superior colliculus in rats produces orienting responses, as it does in a number of species. However, other studies have reported movements resembling avoidance and escape, which are not characteristic of collicular stimulation in other mammals. This apparent discrepancy was investigated by systematically recording the effects on head and body movements of electrical stimulation at a large number of sites throughout the superior colliculus (SC) and surrounding structures.

It was found that the nature of the movements observed depended on the location of the stimulating electrode. Contralateral head and body movements resembling orienting and approach were obtained from sites in the intermediate and deep layers in rostral colliculus, the intermediate white layer and immediately surrounding tissue in central colliculus, and in all layers except deep white in caudal colliculus. At the remaining responsive sites, movements resembling avoidance and escape were obtained. The most common response was an ipsilateral cringelike movement of the body that developed into ipsilateral locomotion, followed by running and jumping as the current was increased. These movements were obtained from sites in the superficial and intermediate layers rostrally; from the intermediate gray and the medial superficial and deep layers in central colliculus; and from the deep layers and underlying tegmentum caudally.

The distributions of sites, together with evidence from other studies, suggested the following conclusions: (1) Within the superficial layers, avoidance responses were obtained from a region of the superior colliculus that appeared to represent the upper visual field, whereas orienting responses were obtained from a region apparently representing the lower visual field. (2) Stimulation of the area containing the cells of origin of the predorsal bundle produced orientation and approach movements, whereas the avoidance and escape movements were probably mediated by parts of the ipsilateral descending pathway. (3) The stimulation-induced avoidance and escape may reflect the importance of such responses to visual "events," particularly in the upper part of the visual field, in animals, like rats, with many predators.

It is widely accepted that the mammalian superior colliculus (SC) is involved in the production of visually triggered orienting movements. Part of the evidence for this view is that electrical stimulation of the SC can produce appropriate movements of the eyes and head (for recent reviews, see Chalupa, 1984; Wurtz and Albano, 1980). Although much of this work has been carried

\footnotetext{
Received Mar. 11, 1985; revised June 25, 1985; accepted July 2, 1985.

This work was supported in part by Science and Engineering Research Council Grant GR/C 46963. N.S. was supported by an Overseas Research Student grant from the Committee of Vice-Chancellors and Principals of the Universities of the

U.K. We thank Ms. Iona Hodges for histological assistance.

Correspondence should be addressed to Dr. Dean.

Copyright (c) 1986 Society for Neuroscience 0270-6474/86/030723-11\$02.00/0
}

out on cats and monkeys, in rats too collicular stimulation can induce movements of the eyes, head, and body that resemble orientation and approach (Imperato and Di Chiara, 1981; Kilpatrick et al., 1982; McHaffie and Stein, 1982; Weldon et al., 1983).

However, these are not the only movements that have been reported to follow collicular stimulation in rats. In a number of studies, electrical stimulation of the rat $\mathrm{SC}$ has produced escape or other responses characteristic of aversive stimulation (Olds and Olds, 1962, 1963; Olds and Peretz, 1960; Schmitt et al., 1974; Stein, 1965; Valenstein, 1965; Waldbillig, 1975). Because electrical stimulation affects axons as well as cell bodies and dendrites, the substrate of these escape or avoidance responses could have been either fibers passing through the SC or the collaterals of fibers that terminatc clsewhere in the brain. But similar responses are also produced by collicular microinjection of GABA antagonists (Cools et al., 1983, 1984; Kilpatrick et al., 1982; Redgrave et al., 1981), which suggests a contribution from local neuronal processes.

These results raise a number of questions. Why do some studies report orienting movements, and others avoidance or escape responses? If the mammalian $\mathrm{SC}$ is exclusively concerned with orientation, why are defensive movements produced at all? The purpose of the present experiment was to try to clarify these issues by providing a systematic description of the movements of the head and body elicited by stimulation at different locations within the $\mathrm{SC}$ and surrounding structures in rats.

Despite the advantages of chemical stimulation mentioned above, we decided to stimulate the colliculus electrically on the grounds that the intensity and duration of the stimulation could be precisely controlled. This made it possible to control the intensity and duration of the elicited movements, which had two benefits. First, as the current was raised in small steps, the component parts of what became complex head and body movements appeared in sequence, and were thus much easier to discern. Second, in the case of avoidance movements, the stimulation could be terminated if the response appeared likely to cause discomfort to the animal. Some of the results have been reported in abstract form (Sahibzada et al., 1984).

\section{Materials and Methods}

\section{Subjects and surgery}

The subjects were 49 male hooded Lister rats weighing $300-450 \mathrm{gm}$ at the time of surgery. Each animal was anesthetized with chloral hydrate $(4 \% ; 8-10 \mathrm{ml} / \mathrm{kg}$ ), after which either a single movable electrode (Miliaressis, 1981) or bilateral fixed electrodes were stereotaxically implanted into the SC or surrounding structures. Both types of electrode were made out of 00 -gauge stainless steel pins $(0.31 \mathrm{~mm}$ diameter $)$ coated with epoxy resin (Clarke Electromedical), except for the cross-sectional area at the tip. The stereotaxic coordinates used for implantation were in the range AP -5.3 to $8.3 \mathrm{~mm}$ posterior to bregma; $L 0.0-2.5 \mathrm{~mm}$ with respect to midline; DV -2.0 to $-7.0 \mathrm{~mm}$ below the surface of dura (dorsal surface of skull level; coordinates from atlas of Paxinos and 
Watson, 1982). Each region was mapped with both fixed and movable electrodes. The electrodes were maintained in position by securing them with cranioplastic cement to anchor screws embedded into the skull.

\section{Testing procedures}

At least 1 week after surgery each animal was placed in a small, clearsided Perspex box $(31 \times 26 \times 30 \mathrm{~cm})$, the floor of which was covered with sawdust. One of the implanted electrodes was connected via a mercury swivel (Campden Instruments) to a constant current pulsegenerating system (Neurolog); a skull crew protruding above the cranioplastic cement served as the indifferent pole. The integrity of the stimulating circuit was continually monitored by measuring the voltagc drop across a $10 \mathrm{k} \Omega$ resistor in series with the rat.

The testing session comprised a series of trials, separated by at least $90 \mathrm{sec}$, in each of which the animal was stimulated with a $1 \mathrm{sec}$ train of negative monopolar square-wave pulses $(0.2 \mathrm{msec})$ at a frequency of $100 \mathrm{~Hz}$. On successive trials the stimulating current was systematically increased in nominal $10 \mu \mathrm{A}$ steps. Subsequent calibration showed that the actual steps were close to $8 \mu \mathrm{A}$, and the maximum current used was $160 \mu \mathrm{A}$. A trial was initiated by the experimenter only when the animal was observed to be completely still. A testing session was terminated either when the stimulating current reached $160 \mu \mathrm{A}$ or when the bodily movement elicited by the stimulation was sufficiently rapid to cause the animal's feet to slip in the sawdust. A simple ascending series of currents was chosen to determine behavioral thresholds. Habituation was not thought to pose a problem with these testing procedures because pilot investigations indicated that within- and across-session threshold determinations of responses elicited by SC stimulation were remarkably stable: For example, elicited movements showed no appreciable decrement after a series of 20-30 stimulation trials spaced only $10 \mathrm{sec}$ apart.

Each trial was recorded on video tape with a camera mounted $97 \mathrm{~cm}$ directly above the floor of the Perspex box. The logic system that controlled the stimulation train duration was used to switch on a $12 \mathrm{~V}$ bulb in view of the video camera. The tapes were analyzed for head and body movements elicited by the central stimulation.

In animals with bilateral implants, the order of testing right- and lefthand electrodes was counterbalanced, whereas the movable electrodes were lowered an additional $0.5 \mathrm{~mm}$ between test sessions, with the animals lightly ancsthetized with ether. At least $24 \mathrm{hr}$ was allowed for animals to recover from the ether anesthesia before testing a new site. With this system, up to six sites were successively tested in a single animal.

After completion of behavioral testing the animals were killed while anesthetized and the exact location of each electrode tract was determined using conventional histological procedures. For the fixed electrodes, evidence of the deepest penetration of the electrode into tissue was taken as the site of stimulation and marked as such on coronal sections from the atlas of Paxinos and Watson (1982). For the movable probes, the same procedure was used to identify the deepest site tested; the more dorsally located sites on the same tract were determined using the scale at the side of each section in the atlas. In some cases there was clear evidence in the histological material that the surface of the SC had been depressed by the incremental descent of the movable electrode. In such instances, the extent of the depression was estimated and due allowance made in the reconstruction of the relevant sites of stimulation. It was this factor that led us to ensure that all areas of interest were surveyed with both fixed and movable probes.

\section{Results}

This section is in four parts, on the topics of (1) why certain stimulation-induced responses were excluded from the data analysis; (2) initial responses. Very low current levels did not produce movements of the head or body: Such movements only emerged as the current was raised. The nature of these initial responses, and the anatomical distribution of the sites that produced them, are described; (3) subsequent responses. As the current was further increased, the initial response pattern either speeded up or changed into a new pattern. The changes that occurred and the anatomical distribution of sites that produced them are described; (4) the anatomical distribution of thresholds for the various movements that were observed (whether as initial or subsequent responses), and, where appropriate, how the direction and amplitude of movements varied with electrode position.

\section{Responses excluded from analysis}

The focus of interest of the experiment was head and body movements resembling either orientation or avoidance that could be directly elicited by stimulation of the SC. Other responses were therefore excluded from the data analysis, for example (1) movements of eyes, pinnae, or vibrissae (see McHaffie and Stein, 1982; Stein and Clamann, 1981); (2) "rebound" responses appearing only at stimulus offset; (3) responses obtained from the 50 sites tested in the cortex and hippocampus overlying the tectum. In fact, stimulation at most $(n=29)$ of these forebrain sites failed to produce any observable reaction within the range of current tested: From the remainder, stimulation elicited forward exploratory movements reminiscent of those produced by rewarding stimulation of the diencephalon (Redgrave and Horrell, 1976) and distinct from movements evoked by stimulation of midbrain and pons (see below).

One additional response was excluded for a different reason. It was our impression that at some collicular sites the lowest threshold effect of stimulation was to suppress spontaneous movement-that is, to cause the animal to "freeze" (Dean et al., 1982; Gabriel et al., 1981; Kilpatrick et al., 1982). Freezing was of interest because, like avoidance and escape, it can be a defensive response to potentially aversive stimuli; however, its systematic study requires a background of continuous movement that was unavailable in the present experiment.

\section{Initial responses}

Only 32 of the 258 brain stem sites investigated produced no head or body movements with a stimulating current of $160 \mu \mathrm{A}$. Twenty of these sites were within, or resting on, the superficial layers of the SC (Fig. 1). Analysis of the video tapes indicated that, despite some individual variability, the initial responses evoked at the remaining sites had sufficient features in common for them to be categorized into five distinct patterns, two of which were observed much more frequently than the others.

1. Contralateral head movement, sometimes accompanied by a contralateral movement of the upper body (76 of 163 collicular sites). These movements (Fig. $2 A$ ) resembled the orienting head movements made by rats to stimuli in the contralateral visual field, i.e., in that area of the field represented by the SC that was being stimulated.

These orientation-like head movements were obtained from sites within the SC that varied systematically with the rostralcaudal plane. Thus, in the rostral colliculus (AP - 5.3 and -5.8), head movements were almost entirely confined to the intermediatc and decp collicular laycrs. At an intermediatc level (AP -6.3 ), head movements were largely centered on the intermediate white layer and directly adjacent tissue. At more caudal levels, they became the predominant lowest threshold response in all SC layers, except the deep white layer. The main areas producing orientation-like responses in structures surrounding the SC ( 29 sites) were the lateral central gray and adjacent mesencephalic reticular formation.

2. An ipsilateral body movement (53 of 163 collicular sites). This movement was rarely accompanied by a contralateral head movement (six sites). It could appear either as a lateral roll of the body or a sinking of the animal onto its haunches; most frequently it was a combination of these two simple forms in which the animal would move both ipsilaterally and backwards (see Fig. $2 B$ ). The immediate impression given by these movements was that of cringing or flinching, like the movements made in response to the experimenter's hand by a rat unwilling to be picked up. They are subsequently referred to as "cringelike" movements.

The location of sites from which cringelike movements were 
$-5 \cdot 3$

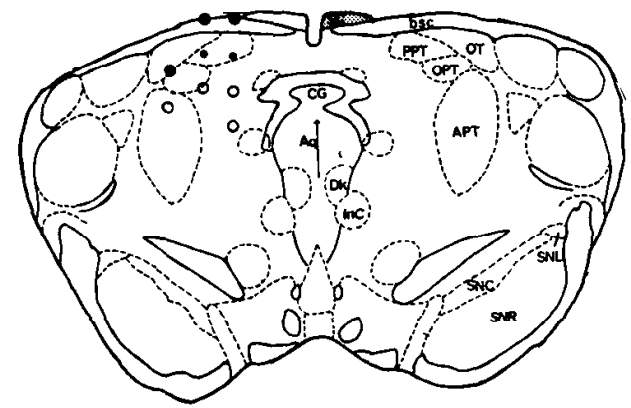

$-5.8$
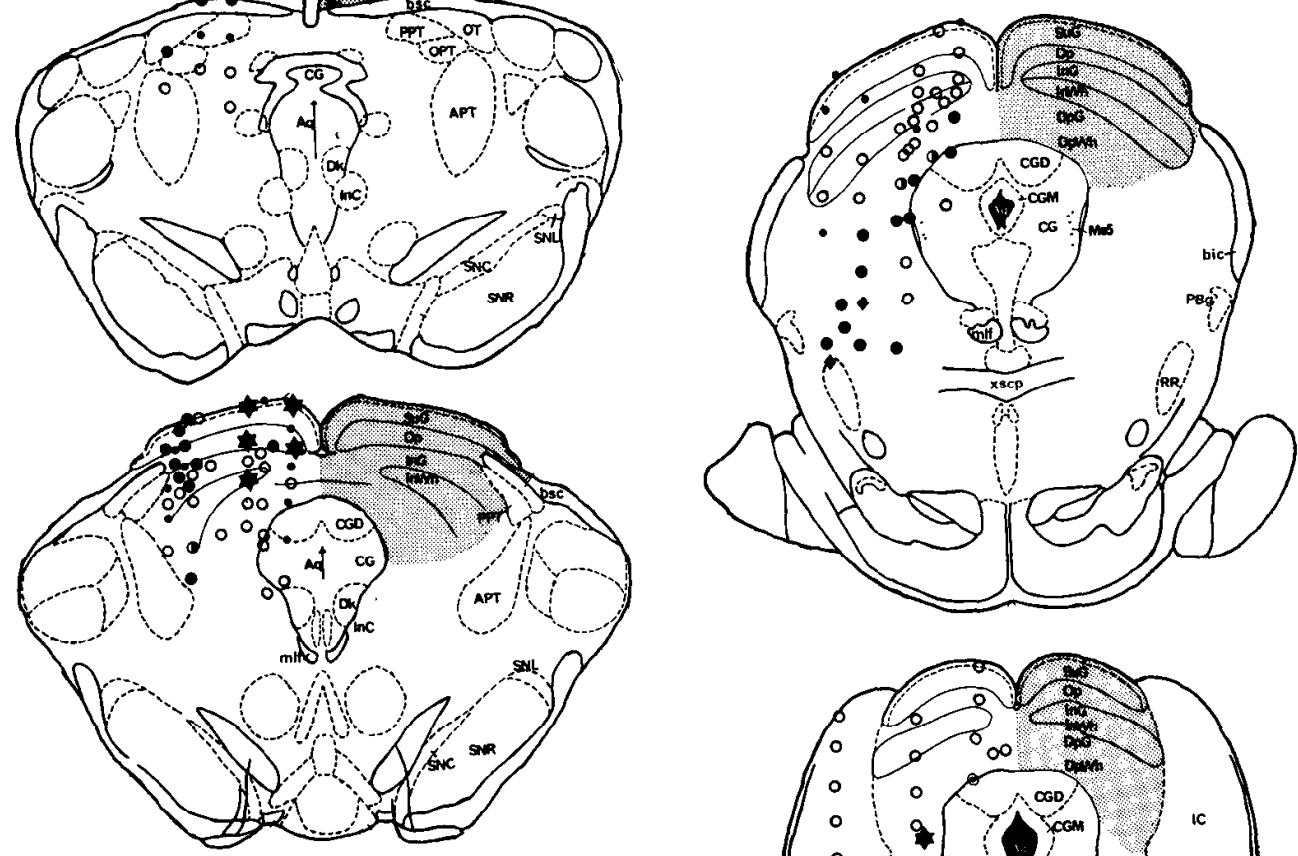

$-6 \cdot 3$
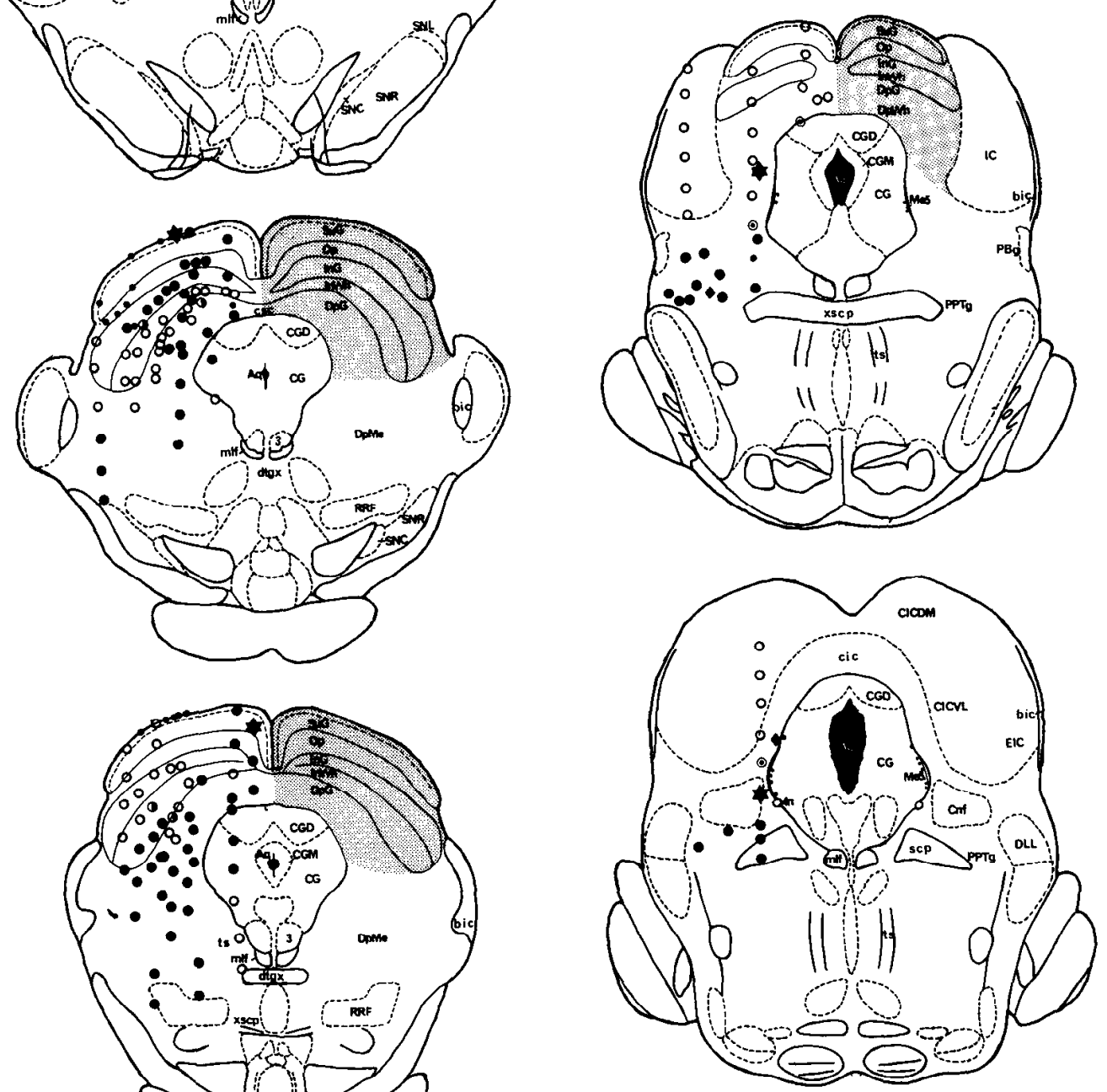

$-6.8$

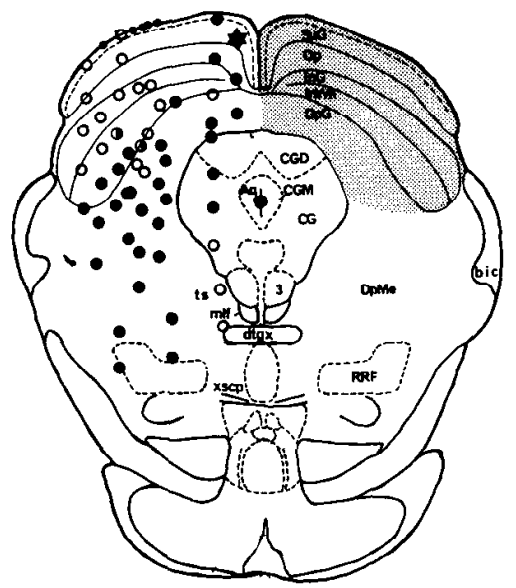

Figure 1. Anatomical distribution of initial response patterns elicited by electrical stimulation within the SC and surrounding structures. The symbols on the map correspond to the following responses (see text): $O$, orienting-like head movement; 9 , cringelike movement of the body; $a$, a cringelike body movement accompanied by orientation-like head movement; $\star$, running or jumping; $\downarrow$, shying-type locomotor movements; $\odot$, approach-likc locomotion; $\bullet$, no response elicited by a stimulating current of $160 \mu \mathrm{A}$. Individual layers of the SC are abbreviated as follows: $S u G$, superficial gray; $O p$, stratum opticum; $I n G$, intermediate gray; $I n W h$, intermediate white; $D p G$, deep gray; $D p W h$, deep white. Abbreviations for all other structures can be found in the atlas of Paxinos and Watson (1982). Numbers in margins ( -5.3 , etc.) refer to millimeters caudal to bregma. 

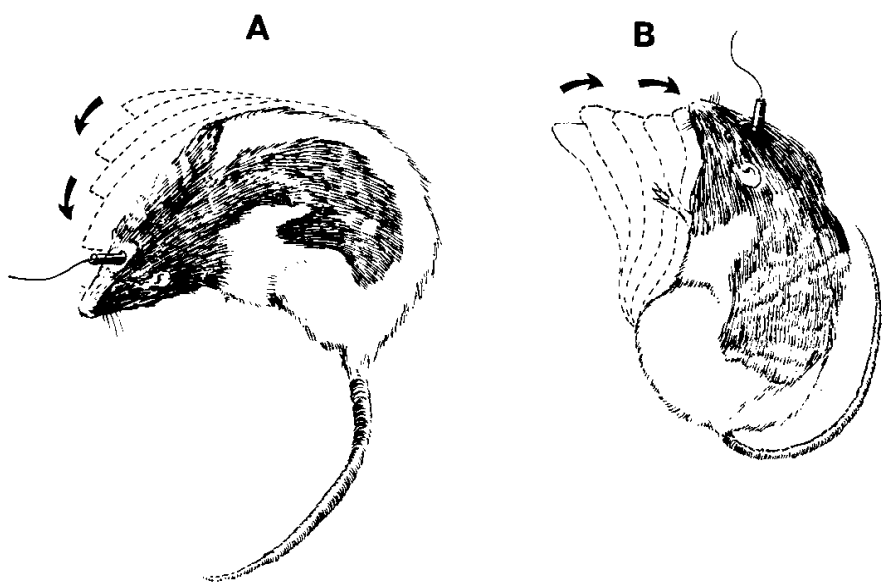

Figure 2. A, Sequence of tracings made from the video screen illustrating the progressive nature of an orientation-like head movement elicited by 1 sec electrical stimulation to the contralateral SC. $B$, Similar illustration of an ipsilateral cringelike movement of the body (see text).

obtained also varied systematically throughout the SC. Rostrally (AP -5.8) these movements were largely confined to the lateral superficial and intermediate layers. At an intermediate collicular level (AP -6.3) there were two distinct areas where cringelike movements were observed: (a) throughout the intermediate gray layer and medial superficial layers; and (b) an area centered on the deep white layer adjacent to the central gray. These two areas sandwiched the orienting responses located predominantly in the intermediate white layer (see above). At more caudal levels the cringelike responses were gradually replaced by orientation-like movements. This occurred first in the intermediatc and superficial layers, then in deep white and gray layers. The cringelike movements were also a common lowest threshold behavior in structures surrounding the SC (53 sites), in particular, the central gray, the caudal mesencephalic, and the pontine reticular formations, and the cuneiform and parabrachial areas.

3. Running or jumping (seven collicular sites). It was our impression that at sites where the threshold movement was running or jumping, subthreshold currents caused freezing, often accompanied by changes in breathing. The movements were typically very rapid and resembled those characteristic of escape or flight (e.g., Barnett, 1958, p. 301). It was because of this class of response that the rule was introduced concerning termination of the test session when the animal's feet slipped on the sawdust; however, the animals appeared quite undisturbed when the response was over (usually within $1 \mathrm{sec}$ of stimulation offset), and they could be handled without difficulty.

Running and jumping were obtained as threshold responses from sites in the superficial and intermediate layers of the medial anterior colliculus, and also from two sites under the caudal SC adjacent to the lateral central gray.

4. Ipsilateral locomotion (four sites). At these sites stimulation produced locomotor movements toward the side of the electrode, although the exact direction might vary somewhat from trial to trial depending on, for example, how close the animal was to a wall of the test chamber. The impression given was that of an animal shying away from a threatening stimulus in the contralateral field, and for this reason the response is referred to as "shying." It was obtained as a threshold response from an occasional site in the caudal midbrain reticular formation, or close to caudal central gray.

5. Forward locomotion with no accompanying head movements. This behavior was obtained as a threshold response from three sites close to caudal central grey.

\section{Subsequent responses}

An example of the way in which response patterns changed with increasing current is shown in Figure 3, which illustrates thresholds for different responses for six sites explored with a movable electrode in the same animal. At the most dorsal site, the threshold response was running and jumping; thus, no further tests were given (see above). At the next most dorsal site, at the boundary between stratum opticum and intermediate gray, the threshold response was a cringelike movement, which was replaced at a higher current by running and jumping. At the third site, in the deep layers, this pattern was interrupted by the appearance of an orienting movement at intermediate current intensities. The site was close to the region in which orientation was the most common response (Fig. 1). At the three most ventral sites, a common pattern was obscrved; first, cringelike movements; then shying; and finally, running and jumping. At the most ventral site, this pattern was preceded by an orienting movement, showing that within the current range tested it was possible to have as many as four movement patterns emerging in sequence.
Figure 3. Qualitative changes in response patterns produced by increasing the stimulating current at each of six midbrain sites within the brain of a single animal. The key for symbols representing different response patterns can be found in the legend of Figure 1.
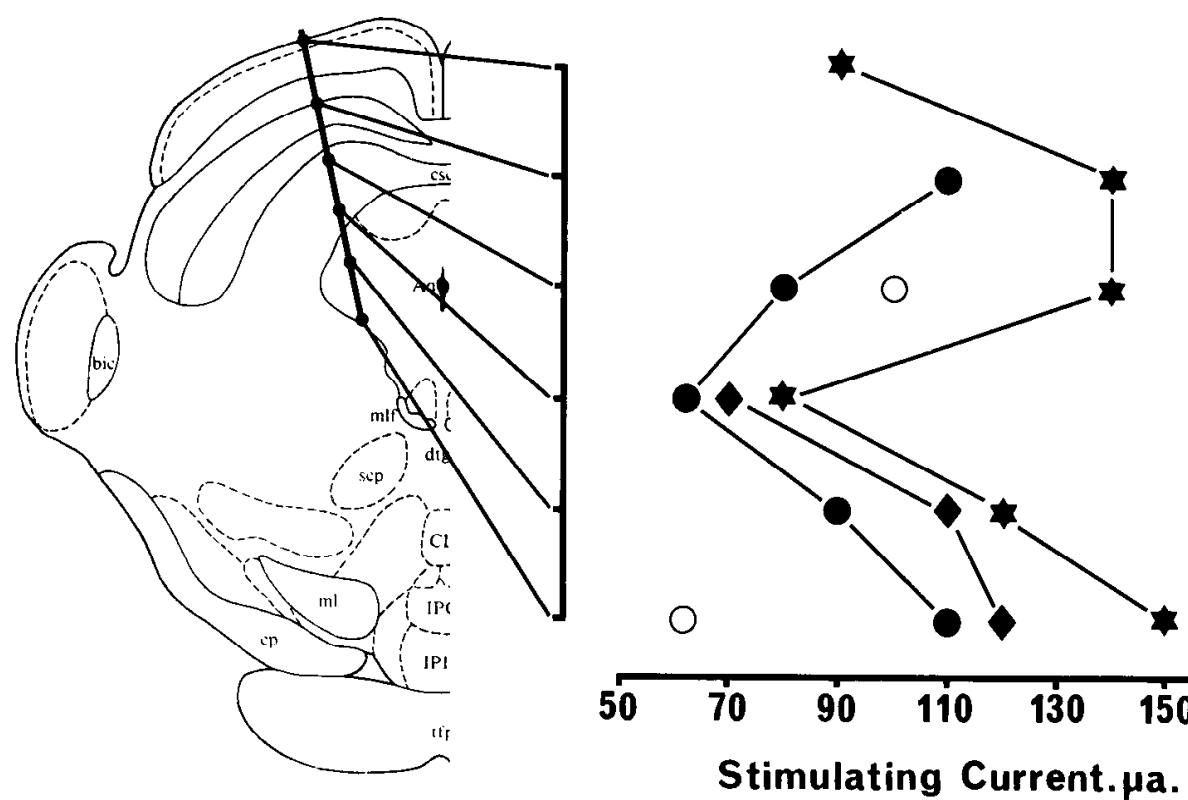

Stimulating Current.ra. 
$-5 \cdot 3$

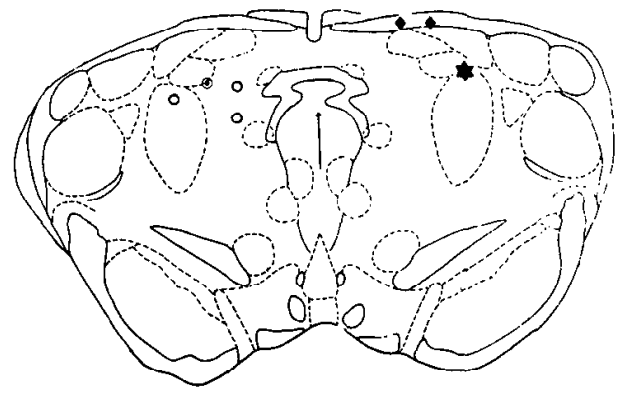

$-5.8$
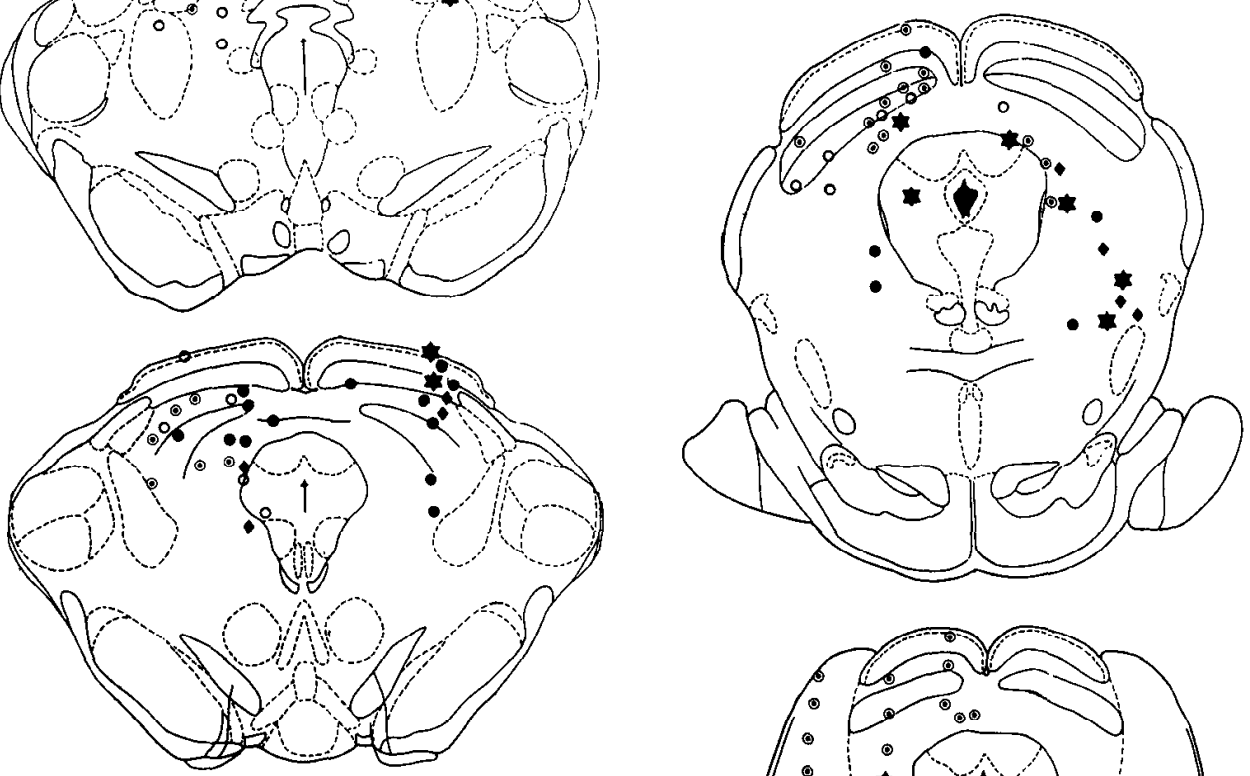

6.3
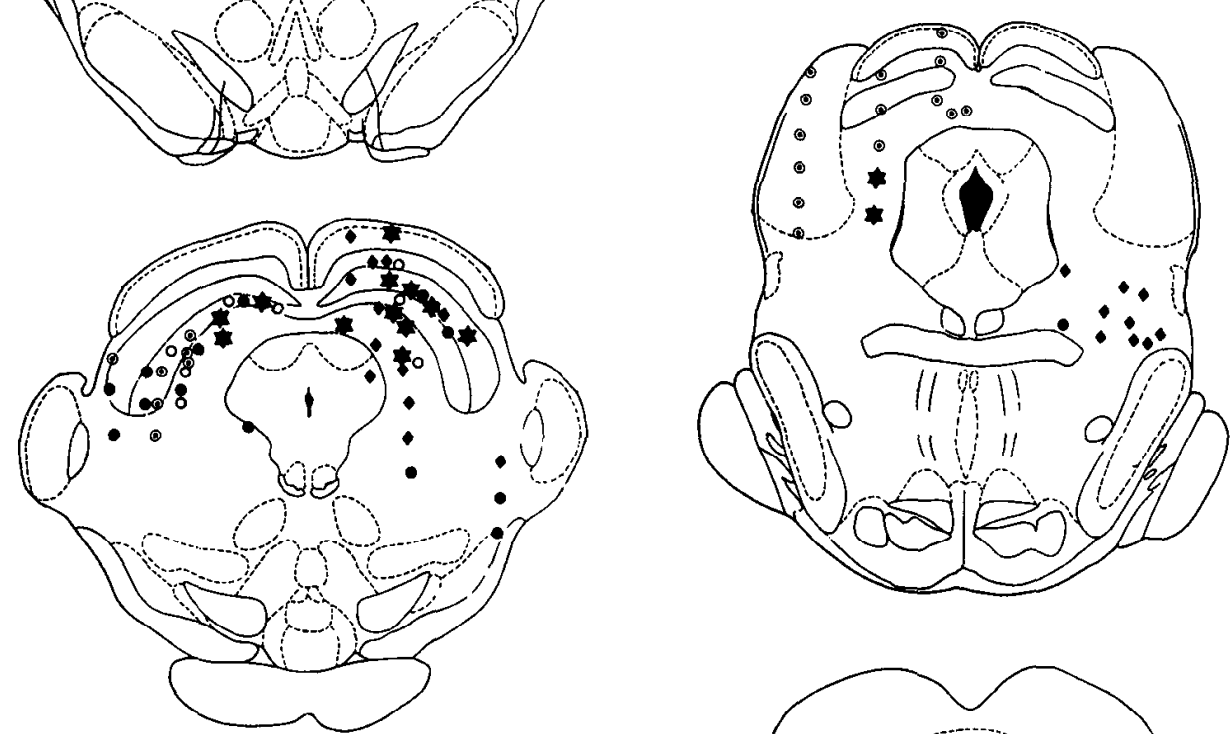

$-6.8$
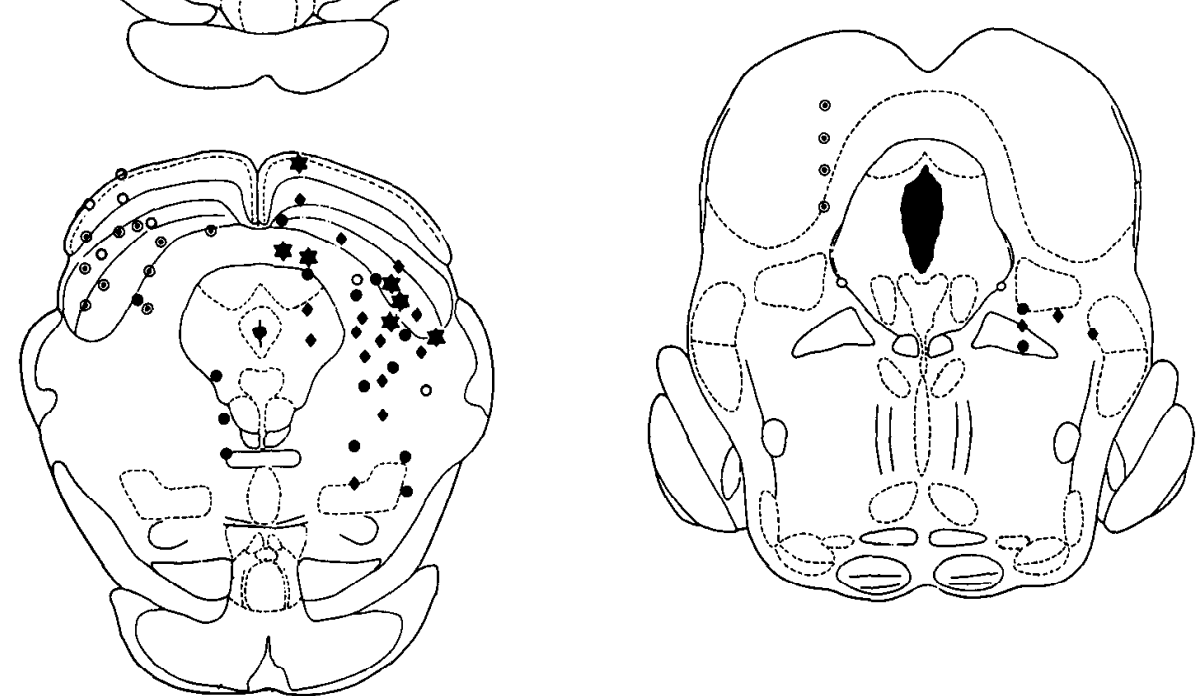

Figure 4. Left, Qualitative changes in the pattern of behavior induced by increasing current at sites where the threshold response was orientationlike movements of the head. Right, Analogous changes at sites where the original response was cringelike movements of the body. The key for symbols representing different response patterns can be found in the legend of Figure 1. Sections as in Figure 1.

The anatomical distributions of sites giving different response patterns as the current was increased is shown in Figure 4. On the left side of the figure are shown sites that initially gave an orienting head movement (76 collicular sites). As the current was increased, one of three changes was observed: (1) The head moved faster, and thus for a greater distance, but no locomotion occurred (18 sites). (2) As the stimulating current was increased, the amplitude of the head movement increased to a point where, in order to continue, the animal had to move its feet ( 38 sites). Additional increases in stimulating current resulted in contra- 

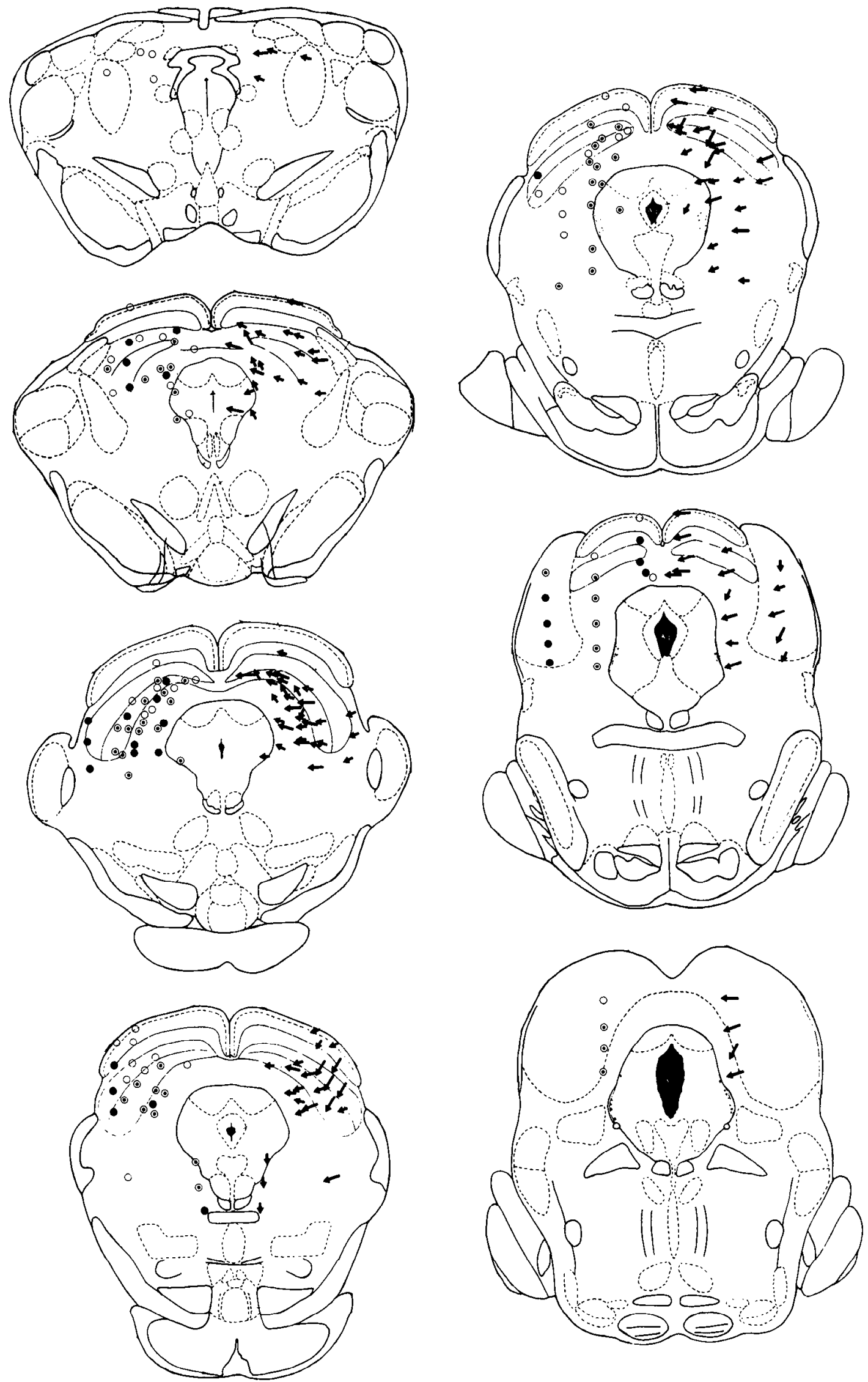

Figure 5. Left, Threshold currents for obtaining orientation-like head movements from the SC and surrounding structures $(\odot, 50 \mu \mathrm{A} ; \odot, 50-85$ $\mu \mathrm{A} ; 0,86-160 \mu \mathrm{A})$. Right, Amplitudes and directions of contralateral evoked head movements. The angle of the movement to the horizontal is represented by the angle of the arrow, and the size of the movement by the arrow length (see text). Sections as in Figure 1. 
lateral turning. Eventually, the turning could become sufficiently rapid to cause the feet to slip in the sawdust, thereby terminating the session. (3) At 20 sites, the orienting head movement was replaced by either a cringelike movement, or running and jumping.

Thus, $74 \%$ of collicular sites that gave orientation as an initial response gave related movements when the current was raised. As Figure 4 shows, this tendency was particularly marked in caudal sites (AP -6.8 to $-7.8,90 \%$ of sites), whereas in the rostral part of the SC (AP -5.8 and -6.3), a greater proportion of second behaviors were movements characteristic of avoidance (cringelike and escapelike, $47 \%$ ). However, at AP -6.3 it was interesting to note that the concentration of orientation sites within the intermediate white and upper part of deep gray layers was retained (Fig. 1).

For sites outside the colliculus, contralateral locomotion was exclusively the second behavior in the inferior colliculus, whereas avoidancelike movements were more common as the second behavior in central gray and underlying reticular formation.

The second behavior at sites initially giving cringelike movements of the body is shown in the right-hand side of Figure 4. Four different outcomes were observed. (1) At a small number $(n=7)$ of collicular sites, an orienting head movement appeared, sometimes accompanied by contralateral locomotion. (2) The movements increased in speed and were accompanied by movements of the feet that allowed the body to continue in a backward ipsilateral direction (13 collicular sites). An unnatural "forced" type of backward ipsilateral rotation thus resulted. (3) The cringelike movement broke away into ipsilateral locomotion, i.e., shying (16 collicular sites). (4) Running and jumping occurred (17 collicular sites).

Thus, $87 \%$ of collicular sites that gave cringelike movements as a threshold response continued to give related movements when the current was raised. More specifically, as Figure 4 shows, within the rostral part of the colliculus (AP -5.3 to -6.8 ), shying-type locomotor movements and explosive escape-like movements were observed with approximately equal frequency as the second behavior ( $n=15$ and 17 , respectively). In the posterior colliculus (AP -7.3 and -7.8 ), only one site initially gave a cringelike movement, and at this site the second behavior was an orienting-like head movement.

In structures surrounding the colliculus, shying-type locomotor movements were more commonly observed as the second behavior in the central gray and reticular formation underlying the anterior colliculus. This was also true for the cuneiform nucleus and the area immediately rostral to it; however, some rapid escape-like movements were obtained in the reticular formation between the cuneiform area and the ventral posterior colliculus.

For the very few sites where the initial movements were either locomotion or shying-type reactions, increases in current simply increased the speed of movement until the feet slipped.

\section{Response characteristics: orienting movements}

The threshold currents for obtaining orientation-like head movements from the SC and surrounding structures, irrespective of the presence or absence of other behaviors, were grouped into three categories and plotted on the left-hand side of sections in Figure 5. The overall impression from these data is that in areas where orientation-like head movements were obtained, any systematic variation in threshold was dwarfed by variability between animals. It is nonetheless possible to discern relatively consistent low threshold sites in the far lateral sector of the SC, a feature that extends caudally into the inferior colliculus. Also, there is a suggestion that sites in the superficial layers of the colliculus had rather high thresholds.

The right side of Figure 5 shows amplitudes and directions

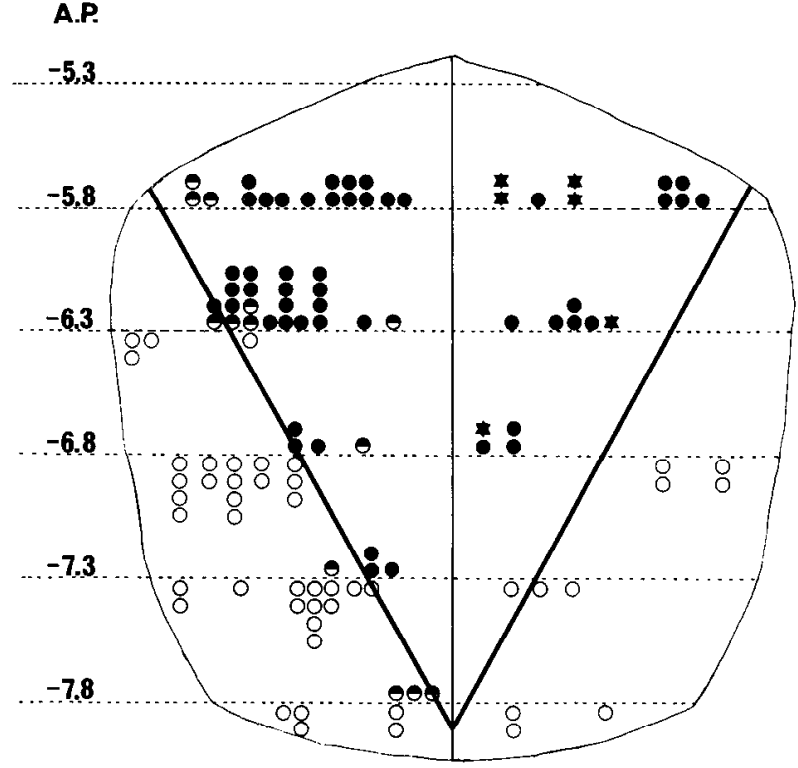

Figure 6. left, Upward, horizontal, and downward orientation-like head movements plotted on a reconstructed surface view of the SC. Responses from all collicular layers are included. The diagonal line approximates the horizontal meridian as indicated by the elicited movements. Right, Threshold response patterns elicited from the superficial layers $(\mathrm{SuG}, \mathrm{Op})$ plotted on a reconstructed surface view of the SC. The key for different responses is in the legend of Figure 1. The diagonal line represents the horizontal meridian, as estimated at left.

of the evoked head movements. Head movements at threshold stimulation were rated as either large $\left(>30^{\circ}\right)$ or small $\left(<30^{\circ}\right)$ independently in horizontal and vertical planes. It can be seen that all evoked head movements were contralateral to the stimulating electrode. In rostral colliculus (AP -5.8 to -6.3 ), of the 36 sites that gave movements with a vertical component, 33 gave upward movement. In the posterior colliculus $(-6.8$ to -7.8 ), the situation was reversed, i.e., out of 38 sites, only five gave upward movement $\left(\chi^{2}=42.5 ; d f=1 ; p<0.001\right)$. Second, when the colliculus was divided into medial and lateral sectors, it was discovered that out of 41 sites in the medial section, 26 gave upward movement, whereas in the lateral sector, only 11 of 33 sites did so $\left(\chi^{2}=5.47 ; d f=1 ; p<0.02\right)$. Thus, as the left-hand side of Figure 6 makes clear, orienting movements obtained from sites in rostromedial colliculus had an upward component, whereas in the posterior and lateral regions, head movements were predominantly downward.

When a similar analysis was done with the amplitude of elicited head movements, it was found that in only 12 of 45 sites in the anterior sections $(-5.8$ to -6.3$)$ were the movements large, whereas in posterior sections $(-6.8$ to -7.8$), 24$ out of 45 were large $\left(\chi^{2}=5.60 ; d f=1 ; p<0.02\right)$. When the analysis was performed on medial and lateral sectors, it was found that large and small movements were essentially equally distributed $\left(\chi^{2}=0.42 ; d f=1 ; p>0.7\right)$. Thus, the amplitude of orientationlike head movements elicited by collicular stimulation increases at more caudal sites.

\section{Response characteristics: movements other than orienting}

The thresholds for cringe-like movements, shying, and running and jumping are shown in Figure 7 . Again, there was considerable variability between animals, so that thresholds were classified simply as either high or low. For stimulation sites within the SC, the low-threshold sites for all three responses were generally located in the deep layers. This sensitive region extended into the underlying reticular formation directly adjacent to the 

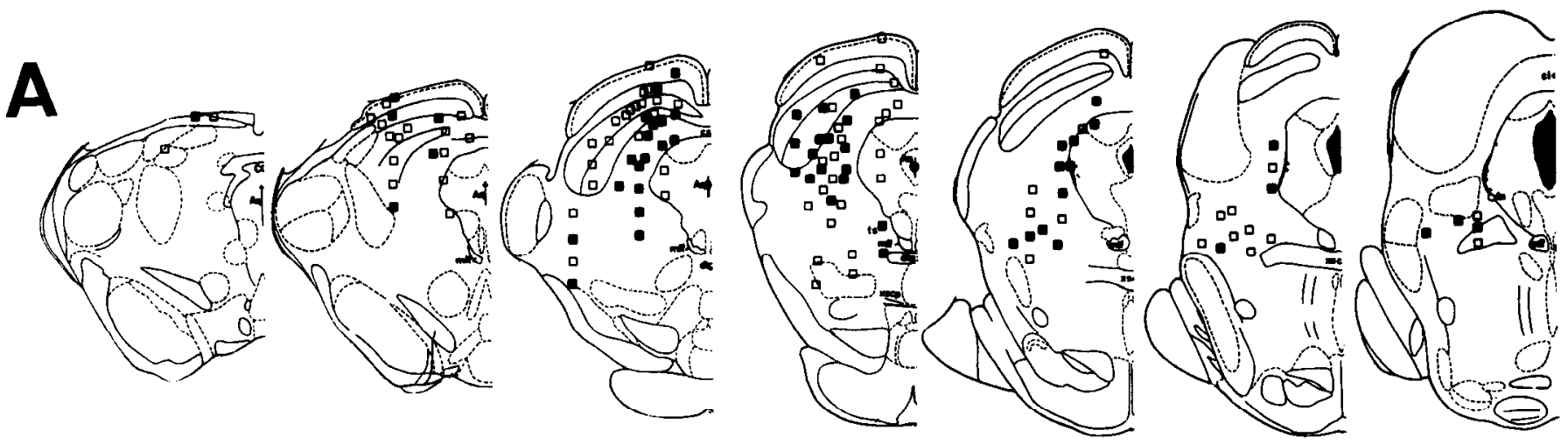

B
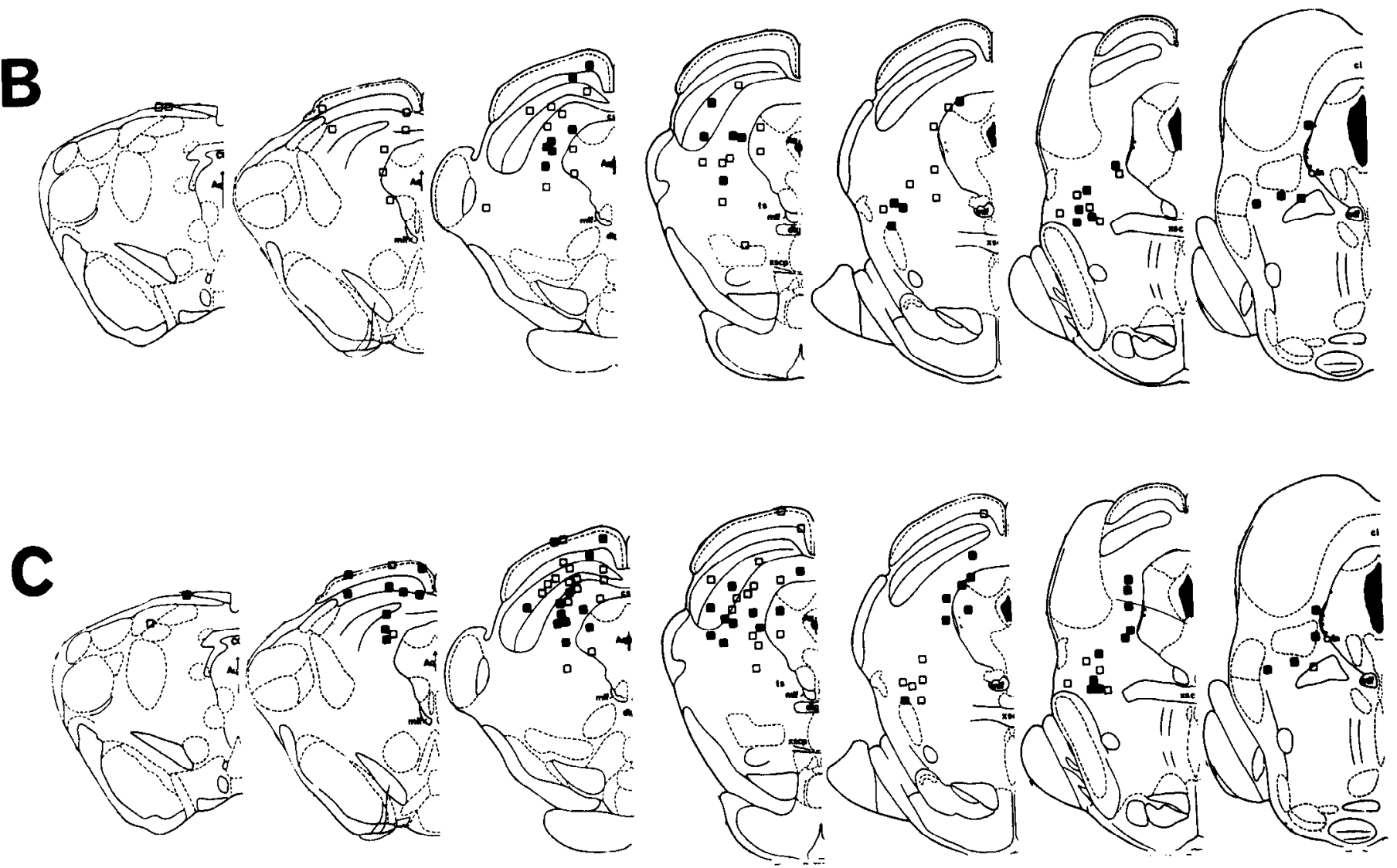

Figure 7. Thresholds for avoidance-like movements elicited from the SC and surrounding structures. For the Cringe $(A)$ and Shy $(B)$ maps: $85 \mu \mathrm{A} ; \square, 86-160 \mu \mathrm{A}$. For the Running $(C)$ map: $\square, 120 \mu \mathrm{A} ; \square ; 121-160 \mu \mathrm{A}$. Sections as in Figure 1.

lateral central gray. The principal exception to this was a sensitive area in the superficial layers of the anterior colliculus, which containcd low-threshold sites for cringe- and escape-like movements.

The cringelike movements entailed a movement of the body into the posterior-ipsilateral quadrant. The direction of this movement (categorized into three classes: purely ipsilateral, purely backward, ipsilateral and backward) was not consistently related to location of stimulation site within the SC. This was also the case for shying and escapelike movements, which, in addition, tended to vary in topography depending on the animal's location in relation to the walls of the testing box.

\section{Discussion}

These results suggest that electrical stimulation of the rat SC can produce one of two quite different patterns of head and body movement, depending primarily on the position of the stimulating electrode.

One pattern was characterized by a contralateral head movement at low currents, which was often accompanied by forward locomotion or turning as the current was increased. Given the representation of space within the $\mathrm{SC}$, such movements can be interpreted as orientation and approach toward a contralateral stimulus. Similar head and body movements have previously 
been reported to follow chemical stimulation of the colliculus in rats (Imperato and Di Chiara, 1981; Kilpatrick et al., 1982; Weldon et al., 1983) and related movements of eyes, pinnae, and vibrissae to follow electrical stimulation (McHaffie and Stein, 1982).

The second pattern was characterized by ipsilateral body movement at low currents, which could turn into ipsilateral walking and finally running and jumping at higher currents. At a small number of collicular sites the running and jumping appeared without prior movements. Given the representation of space within the superior colliculus, and the form of the movements, these responses resemble avoidance of or escape from a contralateral stimulus. Related movements in response to both electrical and chemical stimulation of the superior colliculus in rats have been reported previously (Cools et al., 1983, 1984; Kilpatrick et al., 1982; Olds and Olds, 1962, 1963; Olds and Peretz, 1960; Redgrave et al., 1981; Schmitt et al., 1974; Stein, 1965; Valenstein, 1965; Waldbillig, 1975).

The discussion is concerned with four issues: (1) Is the characterization of the ipsilateral movements as avoidance responses correct? (2) What are the neural substrates that mediate the two patterns of response? (3) What are the functional implications of the two movement patterns? (4) How far do the present results resemble those obtained with collicular stimulation in other species?

\section{Movements resembling avoidance}

The resemblance of the movements produced by stimulation of the SC to avoidance and escape responses may be misleading, at least in the case of cringelike movements. Thus, Schaeffer (1970) reported ipsilateral movements of the head and body to electrical stimulation of rostral colliculus in decorticate rabbits but suggested that the function of those movements was to bring the stimulus onto the central area of the rabbit's laterally placed eye. However, it does not seem likely that the present results could be interpreted in a similar fashion. First, there is evidence that, in all parts of the visual field, rats point their heads at stimuli that they subsequently approach or investigate (e.g., Goss and Wischner, 1956; Lashley, 1932; Overton et al., 1984). In the present study, cringelike movements were obtained from the superficial layers in a region of the SC that gave upwards orienting movements in other layers (Fig. 6). Second, stimuli that cause normal rats to orient can evoke cringing in animals given collicular injection of picrotoxin (Redgrave et al., 1981). In fact, as the drug wears on, the reaction to a visual stimulus that normally elicits orienting changes first to freezing, then to cringing, and finally to increasingly strong flinching, culminating in violent running and jumping.

Thus, cringing appears to be part of a repertoire of defensive responses (see Bandler, 1984), rather than a form of orientation to a particular region of visual space.

\section{Neural substrates}

Determining the neural substrates that mediate the patterns of movement observed after collicular stimulation is hindered by two factors.

The first is that, because of current spread, the effective sites might have been distant from the stimulating electrode. Measurements of current spread from electrodes similar to those used here have indicated that a current of $160 \mu \mathrm{A}$ (the highest used in the present study) may excite neuronal elements $0.36-$ $0.65 \mathrm{~mm}$ distant to the electrode (e.g., Bagshaw and Evans, 1976; Yoemans et al., 1984). In addition, there is evidence for synaptically mediated spread of excitation over $2-3 \mathrm{~mm}$ within the intermediate gray layer of the cat's SC (McIlwain, 1982). However, in the present study there were numerous sites at which the type of behavior observed at low currents persisted when the current was raised, despite the presence nearby of sites giving a different type of response (cf. Figs. 1 and 5). Thus, at these sites it is possible that the spread of excitation to distant regions was not an important factor in determining the pattern of behavioral response.

The second problem of interpretation is that electricity will stimulate not only cell bodies and dendrites, but also axons, including axons of passage and the axon collaterals of fibers afferent to the SC. Because both orientation and avoidance movements have been obtained after microinjection of GABA antagonists into the SC (see the introduction), it is unlikely that the present results were entirely due to stimulation of fibers of passage or axon collaterals. However, the contribution of such stimulation at any individual site is uncertain.

Despite this uncertainty, it is possible to suggest, on the basis of these and other findings, that stimulation of the crossed descending pathway and its cells of origin may he associated with orientation and approach movements:

1. In rats, the bulk of the cells of origin of the predorsal bundle are concentrated within the lateral part of the intermediate white layer (Chevalier and Deniau, 1984; Chevalier et al., 1984; Murray and Coulter, 1982; Redgrave et al., unpublished observations), where electrical stimulation produced orienting head movements (Fig. 1). Similarly, microinjections of GABA antagonists within this region have been reported to induce contralateral head movements and associated turning (Imperato and Di Chiara, 1981; Kilpatrick et al., 1982).

2 . Electrical stimulation from sites in the vicinity of the predorsal bundle as it courses through midbrain and pons has been found to elicit turning (Gobbin and Atrens, 1976; Miliaressis, 1981; Miliaressis and Phillipe, 1984; Robinson, 1978). It appears that the movements produced are very similar to those described here: thus, Yoemans et al. (1984, p. 288) state, "At very low currents, head movements could be obtained without body rotation . . . (at higher currents) the rat's head turned within $0.5 \mathrm{sec}$ after the onset of stimulation, then the front paws swept contralaterally in front of the body to initiate the ipsilateral turn." (The ipsilateral direction of the turn is consistent with the pathway having crossed the midline at the sites at which it was stimulated.)

3. Both anatomical and electrophysiological evidence indicates that, at least in cats, the areas of the brain stem in which fibers of the predorsal bundle terminate are involved in the control of head and eye movements (e.g., Anderson et al., 1971; Edwards and Henkel, 1978; Grantyn and Grantyn, 1982; Kawamura and Hashikawa, 1978). This evidence suggests that stimulation of the cells of origin of the crossed descending pathway is sufficient to produce orienting movements of the head and body; it does not indicate whether this pathway is necessary for the colliculus to mediate orientation. In the present study, sites outside the intermediate white layer gave orienting movements. However, as mentioned above, it is impossible to tell whether such sites represent additional output pathways. Damage to the predorsal bundle has been reported to have very severe effects on visually evoked orienting in tree shrews (Raczkowski et al., 1976), but preliminary observations suggest the effects are less pronounced in rats (Overton et al., 1984).

The evidence that implicates the predorsal bundle in orienting also suggests that it does not mediate the avoidance responses. It is possible that these movements may be associated with the ipsilateral descending pathway:

1. The regions within the $\mathrm{SC}$ from which avoidance movements were obtained are those that contain the cells of origin of the ipsilateral descending pathway (Redgrave et al., unpublished observations). This is also the case for the medial sites at which microinjection of GABA agonists gives similar movements (Cools et al., 1984; Kilpatrick et al., 1982).

2. Stimulation at sites within the ipsilateral descending pathway can give movements resembling avoidance or escape (Fig. 
1; Parker and Sinnamon, 1983; Robinson, 1978; Ross and Sinnamon, 1984; Ruth and Rosenfeld, 1977; Sinnamon, 1984; Waldbillig, 1975). Whether different target areas of this massive projection pathway mediate the different kinds of avoidance and escape movement remains to be investigated.

\section{Functional implications}

It is generally agreed that one function of the $\mathrm{SC}$ is the mediation of visually triggered orienting movements. The conclusion that, in rats, stimulating some collicular neurons can evoke defensive responses suggests that an additional function of the $\mathrm{SC}$ in this species is to produce avoidance or escape on receipt of the appropriate sensory stimulation. This conclusion is consistent with evidence that damage to the $\mathrm{SC}$ can seriously impair visually triggered escape (Blanchard et al., 1981; Dean and Redgrave, 1984a; Goodale and Murison, 1975; Merker, 1980).

How are these different, indeed apparently opposing, functions of the SC in rats to be reconciled? Behavioral and electrophysiological evidence indicates that the SC is particularly concerned with peripheral stimuli that move, or suddenly appear (evidence reviewed in Dean and Redgrave, 1984a, b). Ecological considerations suggest it would be very sensible for an animal like the rat not to orient to and approach every transient it sees: Some transients - for example, those produced by a predator-may require immediate defensive responses. The involvement of the SC in both approach and avoidance movements is thus consistent with the view that the structure is concerned with organizing the appropriate initial response to unexpected visual transients (Dean and Redgrave, 1984c).

Such a view implies that the SC must help to implement the rules used by the animal for deciding which response to make. The present data provide a hint about one of those rules. There was some suggestion that movements resembling avoidance were obtained from the superficial layers in a rostromedial segment of the SC (Fig. 6, right). When orienting movements were obtained from some deeper sites within this segment, they had an upward component (Fig. 6, left). It is therefore possible that defensive responses are more likely when an unexpected visual transient appears in the upper field, whereas orienting and approach are more likely when the stimulus appears in the lower. Such a rule would make ecological sense and is consistent with the behavioral observations of Merker (1980) on hamsters.

\section{Other species}

The involvement of the nonmammalian optic tectum in both approach and avoidance is well established (e.g., Vanegas, 1984), and the present results suggest the rat SC may be more similar to the optic tectum in these animals than previously supposed. The evidence that stimulating the SC in other mammalian species can produce defensive responses is, however, somewhat meager (for review, see Dean and Redgrave, 1984c). Schaeffer (1970) obtained defensive responses from collicular stimulation in decorticate rabbits and cats, and cardiovascular changes that might be associated with "defensive arousal" can be obtained from the SC in carnivores (e.g., Hilton, 1982; Schramm and Bignall, 1971). However, in the overwhelming majority of experimental reports on collicular stimulation in cat and monkey, only movements associated with orienting have been mentioned.

There seem to be at least three reasons that might account for the failure to obtain defensive responses in cats and monkeys. First, the stimulation parameters may have been inappropriate in some way. The number of studies involved reduces the plausibility of this suggestion, as do the recent findings that collicular injections of GABA antagonists also fail to elicit defensive responses from either cat or monkey (Hikosaka and Wurtz, 1983; Jaspers and Cools, 1984), despite their great effectiveness for this purpose in rats (see above).

Second, the appropriate efferents do not exist in cat or mon- key. Currently available neuroanatomical evidence suggests that the general pattern of collicular efferents is similar across a wide variety of mammalian species (e.g., Harting and Huerta, 1984). However, there may exist subtle yet crucial differences between rats and other mammals: The pattern of termination of collicular efferents in the rat has yet to be completely described using recently developed tract-tracing techniques. Alternatively, target structures of some collicular efferents may have assumed new functions in cats and monkeys.

Finally, the appropriate efferent pathways do exist in cat and monkey, but in the circumstances under which stimulation experiments are carried out, these pathways are prevented (perhaps by descending inhibitory control from the forebrain) from influencing behavior. Control of this kind could serve a number of functions. For example, the decision to escape from a visual transient depends heavily on context, such as whether the transient occurs in a safe or dangerous environment (e.g., Dean and Redgrave, 1984c; Merker, 1980). It may be that rats are more likely to regard the laboratory environment as dangerous than are highly trained cats or monkeys. There is some evidence that in rats the threshold for obtaining defensive responses from the $\mathrm{SC}$ can be influenced by activity in the forebrain: Destruction of forebrain dopamine systems elevated the threshold for picrotoxin-induced escape by a factor of about 10 (Redgrave and Dean, 1981; cf. Cools et al., 1984).

Currently available evidence is insufficient to decide which of these possible explanations is correct. The issue may be resolved by further investigations of the functions of collicular efferent pathways in the species concerned.

\section{References}

Anderson, M. E., M. Yoshida, and V. J. Wilson (1971) Influence of superior colliculus on cat neck motoneurons. J. Neurophysiol. 34: 898-907.

Bagshaw, E. V., and M. H. Evans (1976) Measurement of current spread from microelectrodes when stimulating within the nervous system. Exp. Brain Res. 25: 391-400.

Bandler, R. (1984) Identification of hypothalamic and midbrain periaqueductal grey neurones mediating aggressive and defensive behaviour by intracerebral microinjections of excitatory amino acids. In Modulation of Sensorimotor Activity During Alterations in Behavioral States, R. Bandler, ed., pp. 369-391, Liss, New York.

Barnett, S. A. (1958) Exploratory behaviour. Br. J. Psychol. 49: 289310.

Blanchard, D. C., G. Williams, E. M. C. Lee, and R. J. Blanchard (1981) Taming of wild Rattus norvegicus by lesions of the mesencephalic central gray. Physiol. Psychol. 9: 157-163.

Chalupa, L. M. (1984) Visual physiology of the mammalian superior colliculus. In Comparative Neurology of the Optic Tectum, $\mathrm{H}$. Vanegas, ed., pp. 775-818, Plenum, New York.

Chevalier, G., and J. M. Deniau (1984) Spatio-temporal organization of a branched tecto-spinal/tecto-diencephalic neuronal system. Neuroscience 12: 427-439.

Chevalier, G., S. Vacher, and J. M. Deniau (1984) Inhibitory nigral influence on tectospinal neurons, a possible implication of basal ganglia in orienting behavior. Exp. Brain Res. 53: 320-326.

Cools, A. R., J. M. M. Coolen, J. C. Smit, and B. A. Ellenbroek (1984) The striato-nigro-collicular pathway and explosive running behaviour: functional interaction between neostriatal dopamine and collicular GABA. Eur. J. Pharmacol. 100: 71-78.

Cools, A. R., B. A. Ellenbroek, and C. van der Heuvel (1983) Picrotoxin microinjections into the brain: A model of abrupt withdrawal 'jumping' behaviour in rats not exposed to any opiate? Eur. J. Pharmacol. 90: 237-243.

Dean, P., and P. Redgrave (1984a) The superior colliculus and visual neglect in rat and hamster: I. Behavioural evidence. Brain Res. Rev. 8: 129-141.

Dean, P., and P. Redgrave (1984b) The superior colliculus and visual neglect in rat and hamster: II. Possible mechanisms. Brain Res. Rev. 8: 143-153.

Dean, P., and P. Redgrave (1984c) The superior colliculus and visual 
neglect in rat and hamster: III. Functional implications. Brain Res. Rev. 8: 155-163.

Dean, P., P. Redgrave, and G. Lewis (1982) Locomotor activity of rats in open field after microinjection of procaine into superior colliculus or underlying reticular formation. Behav. Brain Res. 5: 175187.

Edwards, S. B., and C. K. Henkel (1978) Superior colliculus connections with the extraocular motor nuclei in the cat. J. Comp. Neurol. 179: 451-468.

Gabriel, S., U. Zippel, U. Kolle, H. Gabriel, and E. Jaskulla (1981) Einfluss verhaltensrelevanter Hirnreizung auf das Entladungsverhalten von Neuronen der Pars dorsalis des Corpus geniculatum laterale der Ratte. In Zentralnervensystem: Entwicklung-Storungen-LernenMotivation, K. Hecht, M. Poppei, W. Rudiger, and K. Seidel, eds., pp. 298-302, VEB Deutscher Verlag der Wissenchaften, Berlin.

Gobbin, D. M., and D. M. Atrens (1976) Ipsiversive rotation elicited by electrical stimulation of the mesencephalon: anatomical, physiological and pharmacological considerations. Exp. Neurol. 52: 100109.

Goodale, M. A., and R. C. C. Murison (1975) The effects of lesions of the superior colliculus on locomotor orientation and the orienting reflex in the rat. Brain Res. 88: 243-261.

Goss, E. A., and G. J. Wischner (1956) Vicarious trial and error. Psychol. Bull. 53: 35-54.

Grantyn, A., and R. Grantyn (1982) Axonal patterns and sites of termination of cat superior colliculus neurons projecting in the tectobulbo-spinal tract. Exp. Brain Res. 46: 243-256.

Harting, J. K., and M. F. Huerta (1984) The mammalian superior colliculus: Studies of its morphology and connections. In The Comparative Neurology of the Optic Tectum, H. Vanegas, ed., pp. 687773, Plenum, New York.

Hikosaka, O., and R. H. Wurtz (1983) Effects on eye movements of a GABA agonist and antagonist injected into monkey superior colliculus. Brain Res. 272: 368-372.

Hilton, S. M. (1982) The defence-arousal system and its relevance for circulatory and respiratory control. J. Exp. Biol. 100: 159-174.

Imperato, A., and G. Di Chiara (1981) Behavioural effects of GABAagonists and antagonists infused in the mesencephalic reticular formation-deep layers of superior colliculus. Brain Res. 224: 185-194.

Jaspers, R., and A. Cools (1984) Colliculus superior: GABA-specificity of picrotoxin-induced behavioural effects in cats. Neurosci. Lett. (Suppl.) 18: S236.

Kawamura, K., and T. Hashikawa (1978) Cell bodies of origin of reticular projections from the superior colliculus in the cat: An experimental study with the use of horseradish peroxidase as a tracer. J. Comp. Neurol. 182: 1-16.

Kilpatrick, I. C., G. L. Collingridge, and M. S. Starr (1982) Evidence for the participation of nigrotectal gamma-aminobutyrate containing neurones in striatal and nigral derived circling in the rat. Neuroscience 7: $207-222$

Lashley, K. S. (1932) The mechanism of vision. V. The structure and image-forming power of the rat's eye. J. Comp. Psychol. 13: 173200.

McHaffie, J. G., and B. E. Stein (1982) Eye movements evoked by electrical stimulation in the superior colliculus of rats and hamsters. Brain Res. 247: 243-254.

Mcllwain, J. T. (1982) Lateral spread of neural excitation during microstimulation in intermediate gray layer of cat's superior colliculus. J. Neurophysiol. 47: 167-178.

Merker, B. (1980) The sentinel hypothesis: a role for the mammalian superior colliculus. Unpublished doctoral thesis, Massachusetts Institute of Technology, Cambridge, MA.

Miliaressis, E. (1981) A miniature movable electrode for brain stimulation in small animals. Brain Res. Bull. 7: 715-718.

Miliaressis, E., and L. Philippe (1984) The pontine substrate of circling behavior. Brain Res. 293: 143-152.

Murray, E. A., and J. D. Coulter (1982) Organization of tectospinal neurons in the cat and rat superior colliculus. Brain Res. 243: 201214.

Olds, J., and B. Peretz (1960) A motivational analysis of the reticular activating system. Electroencephalogr. Clin. Neurophysiol. 12: 445454.

Olds, M. E., and J. Olds (1962) Approach-escape interactions in rat brain. Am. J. Physiol. 203: 803-810.

Olds, M. E. and J. Olds (1963) Approach-avoidance analysis of rat diencephalon. J. Comp. Neurol. 120: 259-295.

Overton, P., P. Dean, and P. Redgrave (1984) The effects of superior colliculus lesions and pre-dorsal bundle knife cuts on orientation in the rat. Neurosci. Lett. (Suppl.) 18: S238.

Parker, S. M., and H. M. Sinnamon (1983) Forward locomotion elicited by electrical stimulation in the diencephalon and mesencephalon of the awake rat. Physiol. Behav. 31: 581-587.

Paxinos, G., and C. Watson (1982) The Rat Brain in Stereotaxic Coordinates, Academic, Sydney.

Raczkowski, D., V. A. Casagrande, and I. T. Diamond (1976) Visual neglect in the tree shrew after interruption of the descending projections of the deep superior colliculus. Exp. Neurol. 50: 14-29.

Redgrave, P., and P. Dean (1981) Collicular picrotoxin alleviates akinesia but not sensory neglect in rats with bilateral 6-hydroxydopamine lesions of ventral midbrain. Psychopharmacology 75: 204-209.

Redgrave, P., and R. I. Horrell (1976) Potentiation of central reward by localised perfusion of acetylcholine and 5-hydroxytryptamine. Nature 262: 305-307.

Redgrave, P., P. Dean, W. Souki, and G. Lewis (1981) Gnawing and changes in reactivity produced by microinjections of picrotoxin into the superior colliculus of rats. Psychopharmacology 75: 198-203.

Robinson, T. E. (1978) Electrical stimulation of the brain stem in freely moving rats: I. Effects on behavior. Physiol. Behav. 21: 223231.

Ross, G. S., and H. M. Sinnamon (1984) Forelimb and hindlimb stepping by the anesthetized rat elicited by electrical stimulation of the pons and medulla. Physiol. Behav. 33: 201-208.

Ruth, R. E., and J. P. Rosenfeld (1977) Tonic reticular activating system: Relationship to aversive brain stimulation effects. Exp. Neurol. 57: 41-56.

Sahibzada, N., P. Redgrave, and P. Dean (1984) Head and body movements evoked by electrical stimulation of the superior colliculus in rats. Neurosci. Lett. (Suppl.) 18: S237.

Schaeffer, K. P. (1970) Unit analysis and electrical stimulation in the optic tectum of rabbits and cats. Brain. Behav. Evol. 3: 222-240.

Schmitt, P., F. Eclancher, and P. Karli (1974) Etude des systemes de renforcement negatif et de renforcement positif au niveau de la substance grise centrale chez le rat. Physiol. Behav. 12: 271-279.

Schramm, L. P., and K. E. Bignall (1971) Central neural pathways mediating sympathetic muscle vasodilation in cats. Am. J. Physiol. 221: 754-767.

Sinnamon, H. M. (1984) Forelimb and hindlimb stepping by the anesthetized rat elicited by electrical stimulation of the diencephalon and mesencephalon. Physiol. Behav. 33: 191-199.

Stein, B. E., and H. P. Clamann (1981) Control of pinna movements and sensorimotor register in cat superior colliculus. Brain Behav. Evol. 19: 180-192.

Stein, L. (1965) Facilitation of avoidance behavior by positive brain stimulation. J. Comp. Physiol. Psychol. 60: 9-19.

Valenstein, E. S. (1965) Independence of approach and escape actions to electrical stimulation of the brain. J. Comp. Physiol. Psychol. 60; 20-30.

Vanegas, H. (1984) (Ed.) Comparative Neurology of the Optic Tectum, Plenum, New York.

Waldbillig, R. J. (1975) Attack, eating, drinking and gnawing elicited by electrical stimulation of rat mesencephalon and pons. J. Comp. Physiol. Psychol. 89: 200-212.

Weldon, D. A., L. C. Calabrese, and K. J. Nicklaus (1983) Rotational behaviour following cholinergic stimulation of the superior colliculus in rats. Pharmacol. Biochem. Behav. 19: 813-820.

Wurtz, R. H., and J. E. Albano (1980) Visual-motor function of the primate superior colliculus. Annu. Rev. Neurosci. 3: 189-226.

Yoemans, J. S., R. Pearce, D. Wen, and R. D. Hawkins (1984) Mapping midbrain sites for circling using current-frequency trade off data. Physiol. Behav. 32: 287-294. 